\title{
Determination of Tritium Content in Radioisotope Wastes by a Wet Oxidation Method
}

\author{
Heung Nae Lee, Seung Dae Yang, Kwang Yong Jee, and Se Chul Sohn ${ }^{+*}$ \\ Atwanced Radiation Technology Institute, Korea Atomic Energy Research Institute, Jeonbuk 580-185, Korea \\ ${ }^{\dagger}$ Nuclear Chemistrv Research Division. Korea Atomic Energy Research Institute, Dajeon $305-353$. Korea \\ E-mail: nscsohnakaerire kr \\ Received Mav 20, 2009, Accepted October 15, 2009
}

Key Words: Tritium. Radioisotope, LSC. Wet oxidation method

Tritium is a naturally occurring radioisotope produced continuously in the atmosphere by the neutron interaction of cosmic ray with helium ( ${ }^{4} \mathrm{He}(\mathrm{n}, \mathrm{np})^{3} \mathrm{H}$ ). It is also produced as a by-product or special product in nuclear reactor sy stems. Tritium produced in nuclear power reactors as a result of the fission of heavy nuclei and by neutron interaction with coolants, moderators. and some light elements ( ${ }^{+} \mathrm{Li}$. ${ }^{\circ} \mathrm{Be}$. and ${ }^{119} \mathrm{~B}$ ). ${ }^{j}$ Tritium labeled materials are extensively used as tracers, in density gauges, in teletherapy, and as the self-luminious light sources in industrial, medical educational and research organizations. ${ }^{-}$Tritium is a radioactive isotope of hydrogen and has a half-life of 12.3 years. It decays to ${ }^{3} \mathrm{He}$ by emitting low-energy' beta radiation with an average energy of $5.7 \mathrm{keV}$ and a maximum energy of $18.6 \mathrm{keV}^{3,4}$

In general the amount of tritium present in a sample is measured by three methods: the sample oxidizer method. the bomb oxidation method, ${ }^{6}$ and the wet oxidation method. The sample oxidizer method has been used commercially for the separation of tritium by igniting the sample for a short period of time, i.e. for about $5 \mathrm{~min}$. However in this method. less than $1 \mathrm{~g}$ of the sample can be ignited at a time. If the sample has a low density. there may be difficulty in measurement because this method cannot use large volumes. The bomb oxidation method, on the other hand can handle a larger weight of sample (up to $20 \mathrm{~g}$ ), but
(A)

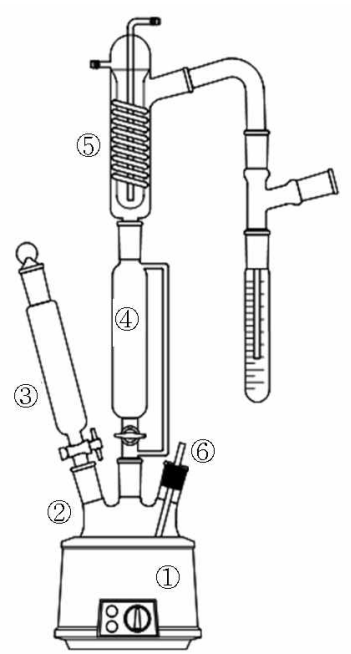

(B)

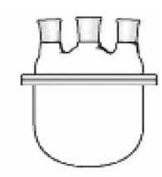

Figure 1. Wet oxidation equipment. (A) A full equipment set and (B) an enlarged round bottom flask. Heating mantle, Round bottom flask, 3 Dropping tumel, 4 HTO collector, Reflux condenser, and 6 , He gas inlet. it produces large quantities of water because of complete ignition of the sample. Hence. a longer time is required to reduce the volume of produced water produced. The wet oxidation method can treat an anount of about $5 \mathrm{~g}$ and can control the volume of the $\mathrm{H}_{2} \mathrm{O}$ produced. However this method cannot handle noncombustible samples such as the glass bottle.

The Ministry of Education. Science and Technology (MEST) in Korea regulates radioisotope (RI) wastes through the Notice $2008-64(100 \mathrm{~Bq} / \mathrm{g})$. Under this regulation the wastes need to be self-disposed by a nuclear enterprise. During this process of self-disposal, the volatile radionuclides $\left({ }^{3} \mathrm{H},{ }^{14} \mathrm{C},{ }^{3-} \mathrm{P} .{ }^{25} \mathrm{~S}\right.$, ${ }^{125} \mathrm{I},{ }^{131} \mathrm{I}$. etc.) present in the wastes are the difficult-to-measure (DTM) radionuclides. Since the wastes are composed of both scissile and unscissile samples. they need to be measured using an established method.

In this study. the wastes generated from various institutes or industries were classified as combustible and non-combustible materials. Some examples of the saniples are vials. pipette tips. tubes. syringes papers. bottles. etc. The radioisotope (RI) wastes containing tritium were chemically separated and analyzed by a wet oxidation method modified for open vessel equipment. which was capable of handling samlples of large size and weight (Figure 1).

The background count rate and specific activity were evaluated from the detection linit $\left(\mathrm{L}_{\mathrm{D}} \text {. cpn }\right)^{8}$ and the nininum detectable activity (MDA. Bq/g). ${ }^{\text {joll1 }}$ respectively.

$$
\begin{aligned}
& \mathrm{L}_{\mathrm{D}}(\mathrm{cpm})=2.71+4.65 \sqrt{\mathrm{C}_{\mathrm{b}} \mathrm{T}_{\mathrm{b}}} \\
& \mathrm{MDA}(\mathrm{Bq} / \mathrm{g})=\frac{2.71+3.29 \sqrt{\mathrm{C}_{\mathrm{b}} \mathrm{T}_{\mathrm{b}}\left(\mathrm{l}+\mathrm{T}_{\mathrm{s}} / \mathrm{T}_{\mathrm{b}}\right)}}{\varepsilon_{\mathrm{Efr}} \times \mathrm{W} \times \mathrm{T}_{\mathrm{s}} \times 60}
\end{aligned}
$$

$\mathrm{C}_{\mathrm{b}}$ : Background count rate (cpm). $\mathrm{T}_{\mathrm{b}}$ : Background counting

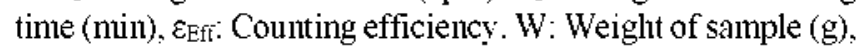
and $T_{5}$ : Sample counting time (min).

The MDA values of the solid samples for tritium counting were measured to be $-1 \times 10^{\circ} \mathrm{Bq} / \mathrm{g}$. For the counting time of $30 \mathrm{~min}$, the counting efficiency was $30 \%$. And the mass was about $20 \mathrm{~g}$. As shown in the equation 2 . the counting efficiency ( $\left.\varepsilon_{\mathrm{Eff}}\right)$ was influenced by the MDA value at the same counting time ( 30 min) and the same weight $(20 \mathrm{~g})$. If the count rate of the sample is below $\mathrm{L}_{\mathrm{D}}$. it means that the activity of the sample is not detectible (N.D.). Even if the count rate is over $L_{D}$. if the 
Table 1. The measurement of tritiun ( $12.17 \mathrm{~Bq})$ counting for sinnulated solid wastes

\begin{tabular}{ccccc}
\hline Sample & Weight $(\mathrm{g})$ & Exp. $(\mathrm{Bq})$ & Yield $(\%)$ & RSD $(\%)$ \\
\hline Vial & 19.5 & 11.68 & 96.0 & 1.25 \\
Tube & 20.3 & 11.75 & 96.6 & 2.05 \\
Vinyl & 10.1 & 11.67 & 95.9 & 1.56 \\
\hline
\end{tabular}

Table 2. Specific activity for tritimn content in RI wastes of the representative combustible materials.

\begin{tabular}{ccc}
\hline Sample & Type & Activity $(\mathrm{Bq} / \mathrm{g})$ \\
\hline C01 & Vial, Tip & $1.226 \pm 0.454$ \\
C02 & Paper, Vinyl & $2.086 \pm 0.935$ \\
C03 & Tube, Tip & $2.597 \pm 0.099$ \\
C04 & Vial & $6.524 \pm 0.538$ \\
C05 & Vial & $17.24 \pm 3.85$ \\
C06 & Vial & $18.29 \pm 3.64$ \\
C07 & Cotton, Paper & $20.42 \pm 4.21$ \\
C08 & Paper, Vinyl & $21.58 \pm 0.75$ \\
C09 & Vial & $30.07 \pm 8.76$ \\
C10 & Vial & $51.48 \pm 11.93$ \\
C11 & Vial & $619.6 \pm 75.1$ \\
\hline
\end{tabular}

Table 3. Specific activity for tritium content in RI wastes of the representative non-combustible materials.

\begin{tabular}{lcc}
\hline Sample & Type & Activity $(\mathrm{Bq} / \mathrm{g})$ \\
\hline $\mathrm{NCO1}$ & Vial & $3.76 \pm 1.19$ \\
$\mathrm{NCO} 2$ & Tube & $5.95 \pm 2.11$ \\
$\mathrm{NC03}$ & Reagent bottle & $13.70 \pm 1.92$ \\
$\mathrm{NCO} 4$ & Tube & $388.7 \pm 8.7$ \\
$\mathrm{NC05}$ & Vial & $1254 \pm 234$ \\
$\mathrm{NCO} 6$ & Vial & $1598 \pm 170$ \\
\hline
\end{tabular}

specific activity of the sample is below the MDA value. this activity would be regarded as N.D.

The recovery efficiency for tritium of the simulated samples was measured using an open vessel device. The percentage of the counting for tritium was found to be about $96 \%$ with an error tolerance of $(1 \sim 2) \% \mathrm{RSD}$ (Table 1 ). The count rate was monitored in cpm (counts per minute). The cpm was converted to dpm (dis-integrations per minute), which is adjusted with the counting efficiency $(25-30) \%$. Generally. the counting efficiency for tritium is about $35 \%$ if $14 \mathrm{~mL}$ of the cocktail and $5 \mathrm{~mL}$ of water are used as the LSC samples. In this case. the low efficiency was caused by a quencher such as NOx generated from the sample.

The radioisotope (RI) wastes generated from the various organizations were classified into combustible and non-combustible materials. Combustible wastes. of which there were $47 \mathrm{RI}$ samples, were composed of PE vials, PE tubes. papers. Syringes, plastics. reagent bottles. etc. Non-combustible wastes. of which there were 12 RI samples. were ty pically made up of glass objects such as vials. reagent bottles. tubes. etc. The experimental should treat a large weight or volume of the samples to ninimize the matrix effect since most of the samples were large in their size. and furthernore the sanples were heterogeneous. The specific activities of the combustible and non-combustible wastes generated from the various organizations were measured with $\left(1.23 \times 10^{1} \sim 6.23 \times 10^{2}\right)$ and $\left(3.76 \times 10^{1} \sim 6.38 \times 10^{4}\right) \mathrm{Bq} / \mathrm{g}$, respectively. The representative results are shown in Tables 2 and 3. The RSD was less than $30 \%$ except for $\mathrm{COl}(37 \%), \mathrm{C} 02$ $(45 \%)$. and $\mathrm{NC0} 2(35 \%)$ samples. The relatively low RSD was due to the low specific activity and heterogeneous sample type (tube. paper. vinyl. etc). The RI wastes with higher activity than that allowed in the regulation as per the Notice $(100 \mathrm{~Bq} / \mathrm{g})$ were monitored within $15 \%$ for combustible samples and $50 \%$ for non-combustible samples.

In summary. RI wastes with low density and low homogeneity generated from industrial. medical. educational. and research organizations were treated by a wet oxidation method using modified open vessel equipment to measure the activities of tritium. The recovery efficiency of tritium for the simulated experiment was around $96 \%$ with $(1 \sim 3) \%$ RSD. The counting efficiency was measured to be $(25 \sim 30) \%$ and the MDA was found to be $1 \times 10^{-2} \mathrm{~Bq} / \mathrm{g}$. The specific activities for the combustible and non-combustible materials were measured to be $\left(1.23 \times 10^{6} \sim 6.23 \times 10^{3}\right)$ and $\left(3.76 \times 10^{6} \sim 6.38 \times 10^{4}\right) \mathrm{Bq} / \mathrm{g}$. respectively. The RSD of the specific activity was typically less than $30 \%$. Hence, it can be concluded that a wet oxidation method using open vessel equipment can be used both for the treating the samples of low density such as the paper and vinyl and the heavy weight samples such as metal and reagent bottles.

\section{Experimental Section}

Reagent. Tritium in the HTO form purchased from Amerisham $\mathrm{Co}$. was used after the activity was diluted to $117 \mathrm{~Bq} / \mathrm{mL}$. The RI wastes used were those generated from the industrial. medical, educational. and research organizations since 1995.

Equipment. Open vessel equipment was manufactured for treating a large weight and/or size in an acidic condition. The tritium contents were determined by a liquid scintillation counter. LSC 2500 TR/AB (Model Chill Pack 1419. Perkin-Elmer). The measured cpn was converted to dpm by adjusting the counting efficiency

The simulation of the solid wastes: $5 \mathrm{~g}$ of $\mathrm{K}_{2} \mathrm{~S}_{2} \mathrm{O}_{8}$ and $0.5 \mathrm{~g}$ of $\mathrm{AgNO}_{3}$ were added to $50 \mathrm{~mL}$ of $1.5 \mathrm{M} \mathrm{H}_{2} \mathrm{SO}_{4}$ solution. $20 \mathrm{~g}$ of the solid wastes (vials. pipette tips. tubes. syringes. paper. glass) and $0.1 \mathrm{~mL}$ the standard tritiun (HTO; $117 \mathrm{~Bq} / \mathrm{mL}$ ) were then added to the solution. After refluxing for $3 \mathrm{~h} L$ the collection of tritium (HTO) was distilled to the collector (Figure 1). $5 \mathrm{~mL}$ of distilled water in HTO form as LSC samples was mixed with $14 \mathrm{~mL}$ of Ultima-Gold XR. The samples and the background were counted by LSC for $30 \mathrm{~min}$ and the count was adjusted by the quenching correction curve.

The distillation of the RI wastes: The same procedure as the simulation experiment was repeated except that in this case (10 30 ) $\mathrm{g}$ of the RI wastes brought from the various organizations was used. The activities of tritium (HTO) produced from the distillation were counted by LSC. This was adjusted by the quencluing correction curve and the background count rate for $30 \mathrm{~min}$ 


\section{References}

1. Hombrook, C. EPRI TR-107201, 1996.

2. Korea Radioisotope Association, Statistics on Radiation Practices in Korea, 2008.

3. Lieser, K. H. Nuclear and Radiochemistm: Fundantentals and Applications VCH publishers, Inc.: New York, NY, 1997.

4. Yoder, T. A. DOE Handbook: Primer on Tritium Safe Handling Practices; U. S. Department of Energy: Washington, D. C., 1994 5. Hou, X. Appl. Radiat. Isot. 2005, 62, 871 .
6. Magnusson, A. Measurement of the Distibution of Organic and Inorganic "C in a Graphite Reflector from a Swedish Niclear Reactor. Department of Physics: Lund University, Lund, 2002.

7. Alun H. J.; Lee, H. N.; Han, S. H. J. Koreon Rodioactine Haste Soc. 2005, 3, 193

8. Currie, L. A. Anal Chem 1968, 40,586

9. Lee, M.-H.; Cho, Y.-H.: Choi, G.-S.: Lee, C.-W.: Shin. H.-S. Anal. Sci. Tech. 2001, $14,64$.

10. Strom, D. J.; Stansbury, P. S. Health Phys. 1992, 63, 630.

11. Nir-El, Y. Health Phys 2001, 80, S22. 